\title{
A Preliminary Inquiry into the Methodologies Employed in Research on ICTs and Society: Prologue ("An Alternate View of Knowledge Negotiation")
}

\author{
Alice Robbin \\ School of Library \& Information Science, Indiana University Bloomington, arobbin@indiana.edu
}

\begin{abstract}
This paper originates in a commitment to write a panel presentation on the methodologies employed in published research on ICTs and society for the 2009 ICTs, Society, and Human Beings conference. The author recognized that this task was not feasible without a rethinking of how to proceed. This paper describes how the author reconceptualized her thinking about how to fulfill her original commitment and offers an example of how we begin to understand what our research question is about.
\end{abstract}

Keywords: conduct of research inquiry, methodology, bibliometrics

Acknowledgement: This essay is a product of the "water cooler effect," the well-known and essential process of arriving at (or negotiating) an understanding of what you "really" intended to research. Your informal social networks remain invisible unless you recognize this principle of research problem identification and knowledge discovery (citation of their published work is typically inadequate for acknowledging this form of contribution). Many thanks for the $\mathrm{H} 2 \mathrm{O}$ stimulation go to my SLIS colleagues Blaise Cronin and Lokman Meho.

Method broadly viewed, is a series of strategies for finding a way to associate the abstractions of theory with the actual social relations [evidence] being mapped, interpreted, or explained by the theory... Techniques for collecting, verifying, and evaluating the validity and reliability of specific kinds of evidence constitute the narrow meaning of "method" and comprise the skills usually taught in a methods course... [Instead, we should consider that] methodological discussions [are] about how to connect evidence to our theories...There is a continuous interplay between theoretical assumptions and the objects of inquiry. "Theory" and "method" form moments, as it were, within the process of inquiry. (Alford, 1998, pp. 12, 13)

\section{Introduction}

My commitment to this panel is to examine the methodologies employed in research on ICTs and society. To frame the task, I want first to follow up on the two references that Hofkirchner makes in the description of the topic of this panel. Not only because they acknowledge and help clarify the difficulty of responding to my mission, which I did not understand fully when I enthusiastically suggested this topic. But also because they point us in the direction of how a study of the methodologies employed in research on ICTs and society might be investigated. These references, an issue of the journal The Information Society ${ }^{1}$ (2005) devoted to whether research on the Internet (aka "Internet studies") might be considered a discipline and the Kim and Weaver

\footnotetext{
${ }^{1}$ The Information Society, volume 21, issue number 4 (2005).
} 
(2002) article that reviews communication research about the Internet, suggest strategies for an examination of the methodologies employed in to make progress on the topic.

Then, I want to describe what I am calling a "prologue" to the commitment I made, which is an alternate way of examining how we understand the work of scholars who carry out research on ICTs and society, which supports Gunilla Bradley's conception of "convergence theory" as a guide to understanding how to approach the topic of "methodologies employed in research on ICTs and society." How I worked through this follows a quite normal trajectory of discovering what the research is "really" about, as Kritzer $(1994,1996 a, 1996 b)$ discusses so vividly in his three must-read articles about discovery and the interpretation of evidence during the research endeavor. I tell my students that I refer to this process as the "stumbling towards Jerusalem" approach. I discuss the preliminary research I conducted, which follows the bibliometrics method of journal impact analysis, to identify the first steps in my study. Finally, I want to conclude with some remarks about what I deem constitutes an adequate study of the methodologies employed, relying on a conception of what the term methodology means that has been identified by the sociologist Robert Alford (see above)

\section{Identifying Research on "ICTs and Society"}

The editor of this special issue of The Information Society directs our attention to: whether "Internet research is an academic 'field' or 'discipline,' what it means to label this field, whether 'Internet research' [studies] is the right name, and what this field might learn from the histories of other interdisciplinary fields" (Baym, 2005, p. 229). I must confess that it does seem a bit strange to me, however, that the identity of a field (discipline) is derived from the name of a technology because, as Markham (2005) points out, "definitions and metaphors construct conceptual boundaries of meaning for [a] field of inquiry, delimiting and protecting over time what counts as Internet and Internet studies" (p. 257). I am ready to concede, however, that the phrase "The Internet" may be "a useful way to refer to many things at once. It stands in for and provides a shortcut to any number of specific, context-based phenomena" (Markham, p. 259). Still, Markham advises us to consider "The Internet" as a powerful metaphor, reminding us that "metaphors are working theories" that "function to delineate what is and is not a part of Internet studies [or Internet-related phenomena], thereby limiting the discipline within particular boundaries" (p. 261). In this instance, the term tends to focus our attention "on the tool and container features of phenomena" (p. 361). And Hine (2005) writes, citing December (1996), that "we need to pay more explicit attention to developing schemas that show where we have common ground" (p. 244). Markham continues in this vein, with his analysis of how the development of an academic discipline "privileges certain ways of thinking about 'the Internet' and marginalizes the voices of alternate theories that will disrupt the stability of the discipline" and that the "organizing features of culture...function hegemonically to guide behavior" ( $p$. 265). Their assessment leads me, as I will explain, to a different way of conceptualizing how to proceed with my study.

Rice's (2005) analysis in the same issue of The Information Society examines recent trends in new media and Internet research. He first searches five major indexing and abstracting databases (EBSCO Business Source Premier, library and information science, SocioFile (sociology), ComAbstracts, and Medline) for the period 1985 through 2003 for the word "Internet" in either the title or abstract to examine the growth in publications (p. 286). ${ }^{2} \mathrm{He}$ finds that the fields of library and information science and business and management "showed the earliest concern with the Internet," but that the other fields are catching up (pp. 286-287). Then he conducts a semantic network analysis of words in the titles and abstracts of papers at the 2003 and 2004 conferences of the Association of Internet Researchers (AOIR). Rice notes in his concluding remarks that the traditional dimensions of social science research topics and social science research or cultural analysis

\footnotetext{
${ }^{2}$ No specific database is provided for "library and information science, so it is unknown to which he refers. It (they) could be LISA: Library and Information Science Abstracts and/or LISTA. There is also another database Communication and Mass Media Complete. No specific identification is provided for "SocioFile."
} 
"represent the primary identity of AOIR" (p. 289). From his multidimensional scaling, he finds that network research and methods form a distinct theme; however, these topics received "less specific use in session titles" (p. 289); in any case, virtually all panelists present "research" and "analysis," so it is unclear how useful these terms are as indicators of what AOIR participants do.

Hofkirchner's second reference is the Kim and Weaver (2002) article whose interest is the medium of the Internet as an emerging interdisciplinary research agenda. The authors conduct a thematic meta-analysis of theories and methodologies of 561 research articles published in academic journals or books indexed in Communication Abstracts between 1996 and 2000 and employ Wimmer and Dominick's (2000) developmental model of media research to organize their analysis. ${ }^{3}$ They categorized the 561 articles into 52 specific research subjects and then into 12 broad categories, with $21 \%(n=118)$ studies addressing multiple subjects (p. 523) (see Table 2 in Kim \& Weaver, p. 526). Of these articles, 149 were identified as employing a quantitative ("numerical or counting procedures") research methodology and 409 were categorized as employing other methods ("nonquantitative") (see Table 3 in Kim \& Weaver, p. 528). ${ }^{4}$ Non-quantitative methods dominated by a ratio of 2.7 to one quantitative article (p. 524). Kim and Weaver find that only $17 \%$ of the 561 were "explicitly about theory" (p. 529) (see Table 4 in Kim \& Weaver, p. 530). Their comparison of research methods and theoretical applications in major and less-circulated communication-related journals indicates that "internet research published in [the major journals] was more likely to be quantitative $(38.2 \%$ vs. $23.7 \%)$ and theory-based $(22.7 \%$ vs. $16.0 \%)$. They note that earlier research had found "more quantitative research articles (particularly survey and content analysis) and few theory-driven or hypothesis- [model-] testing studies" (p. 521). However, although nonquantitative methods studies dominate, the authors find more quantitative studies are conducted that emphasize theory testing and building as a "field" of media studies matures (pp. 531-532).

What can we conclude as it pertains to the disciplinary interests and main topic of discussion of the scholars who contributed to this special issue of The Information Society (2005) and the Kim and Weaver (2002) article? This special issue of 13 contributions is dominated by scholars located in communication studies departments, with two exceptions in sociology, one in a business school, and one in language and literature. With the exception of Rice, these scholars appear to represent the critical, cultural, and interpretive theory turn that dominates the fields of communication (and culture) and science and technology studies. Rice (2005) asserts but does not demonstrate that the topics represent the interdisciplinary nature of Internet studies; however, his study is more about applying a statistical technique than about providing deeper insights about what is called in this journal special issue devoted to "Internet Studies." Kim and Weaver are located in a journalism school, but Weaver can easily be categorized as a political and mass communication scholar and Kim a new media technology and mass communication scholar; neither of them appears to represent the "cultural turn" in communication studies.

Although both the special issue and the Kim and Weaver article discuss the interdisciplinary nature of Internet studies, we do not yet have sufficient evidence of these disciplines, although we can make some educated guesses given the topics that are represented in their meta-analysis. Leydesdorff and Probst (2009) article provides excellent empirical support though a factor analysis of citing and cited studies for the case that communication studies is indeed an interdisciplinary specialty.

As concerns the methodologies employed, critical, cultural, and interpretive studies suggests "cultural analysis" as the principal mode of methodology, as Kim and Weaver's study found. Rice's analysis of the titles and abstracts of the conference papers is unsurprising as an indication of how infrequently the language of methodology or terms associated with types of methodology appears

\footnotetext{
${ }^{3}$ The Wimmer and Dominick organizational model of internet research identifies four phases: Issues for the internet itself (Phase 1); Uses and users of the internet (Phase 2); effects of the internet (Phase 3); and How can the internet be improved? (Phase 4). For a different way of organizing the evolution of new media and communication studies, see Lievrouw (2009).

${ }^{4}$ They categorized the research methods as "quantitative" if the author employed a survey, content analysis, experiment, or empirical secondary data analysis. Non-quantitative or "other" methods included, as examples, issues and problems, historical or philosophical analysis, legal analysis, textual analysis (p. 524).
} 
to have figured in AOIR research. My sense is that "methodology" is not more than, as Rice has coded it, an "application" and a taken-for-granted because the focus of the texts is on a specific substantive topic and, moreover, methodology is not a topic to which attention is generally given. Possibly of greater importance is the narrow conception of what constitutes "methodology." As Alford's (1998) comment suggests, the Kim and Weaver article take a rather narrow view of "methodology," categorizing it according to technique.

Finally, there remains the issue that "Internet studies" may not be an appropriate way to provide an entry into a deeper understanding of what constitutes research on "ICTs and society." I remain doubtful, although agnostic, recognizing that different entry points yield different understandings and contribute critically necessary multi-lens approaches to knowledge discovery. The problem remains, however, that the reference to the "Internet" constitutes a rather narrow conception of technology, focusing attention on computerization and ignoring the variety of technologies that we employ in daily life.

\section{A Different Entry Point}

A third point of entry for understanding the methodologies employed in research on ICTs and society is through the reading habits of experts, those researchers who identify themselves as scholars of ICTs and society. Here I turn for guidance to my colleagues Gunilla Bradley of the School of Information and Communication Technologies at the Royal Institute of Technology in Stockholm and Wolfgang Hofkirchner and his colleagues at the Center for Information and Communication Technology and Society at the University of Salzburg. What makes them excellent candidates for my study is that they are members of centers for research that were explicitly created to foster interdisciplinary research.

Since her first published research in the 1970s, Bradley (2006) has taken a cross-disciplinary and interdisciplinary path for conducting empirical research on "how computerization affects the physical and psychosocial work environment" or, to put it another way, the relationship between "computer technology and structural and social change in work life" (p. 9). Deconstructing the corpus of her work yields the integration of a "people-centred perspective" (p. 2) to "achieve the good society" (p. 197). This perspective relies on the disciplines of psychology, social psychology, sociology (complex organizations, workplace studies, education, family, and professions), health and medicine, and information technology-related disciplines of business administration (management), computer science, and informatics. She extends her disciplinary interests to industrial engineering and design (ergonomics), media studies, communication, and political science (politics, public policy, power, the law, democracy, public administration and management).

Hofkirchner exemplifies a theory-laden approach, but it is theory drawn from a variety of different theoretical and philosophical foundations that rely principally on a "critical" interpretive perspective. These he identifies as: studies of ICTs and society ("Critical Information Society Theory"), the sociology of technology ("Critical Design Theory"), and the study of social thought ("Critical Social Systems Theory"). He extends his interests to the sciences of complexity ("Evolutionary Systems Theory"), information theory ("Unified Theory of Information"), and the philosophy of information, systems philosophy, and social philosophy which integrate the study of practice, theory, and epistemology. ${ }^{5}$ Judging by his articles and conference participations, his disciplinary interests include economics, anthropology, information science, linguistics (semiotics), life sciences, humanities, psychology, computer science, philosophy, information systems, and communication. His colleagues, who also acted as experts for this essay, contribute disciplinary interests that span the social sciences, including psychology, sociology, and political science (politics, governance, public management, law and policy, political economy), and economics (information economics); and

\footnotetext{
${ }^{5}$ In his own words, see his biographical statement: http://icts.sbg.ac.at/media/pdf/pdf1695.pdf
} 
information- and information technology-related disciplines of computer science (artificial intelligence) and business (information systems, knowledge management). ${ }^{6}$

\section{4. "Stumbling Towards Jerusalem": Methodology for Discovery (Prologue)}

There are, as we have seen from my summary of Rice's and Kim and Weaver's analyses, different ways to approach a study that identifies the disciplinary scope of research. But an entry point must be selected in order to gain control over the task of answering the question: "What methodologies are used to conduct research on ICTS and society?" The standard approach used by information scientists is bibliometrics or some form of journal impact or (co-)citation based method for analyzing the intellectual contribution of disciplines and individual scholars. These methods are especially useful for identifying the knowledge "import" and "export" value of disciplines for scholarly work in a particular field as well as the strength of interdisciplinary ties (Cronin \& Meho, 2008). For high-scatter fields, which we would expect of interdisciplinary studies such as ICTs and society, Cronin and Meho note that "scholars typically have to search widely across fields and disciplines to source relevant materials" because the topics are dispersed (p. 552).

The salient issue for me was how to construct a population of journals from which a sample could be drawn for a future study of the methodologies employed by scholars in ICTs and society. I was under considerable time constraints due to the lateness of the acceptance date and the date that our papers were due. A two-stage method was followed. The first stage was to obtain a list of journals that were regularly read by my colleagues on this panel. I wrote on March 17, 2009:

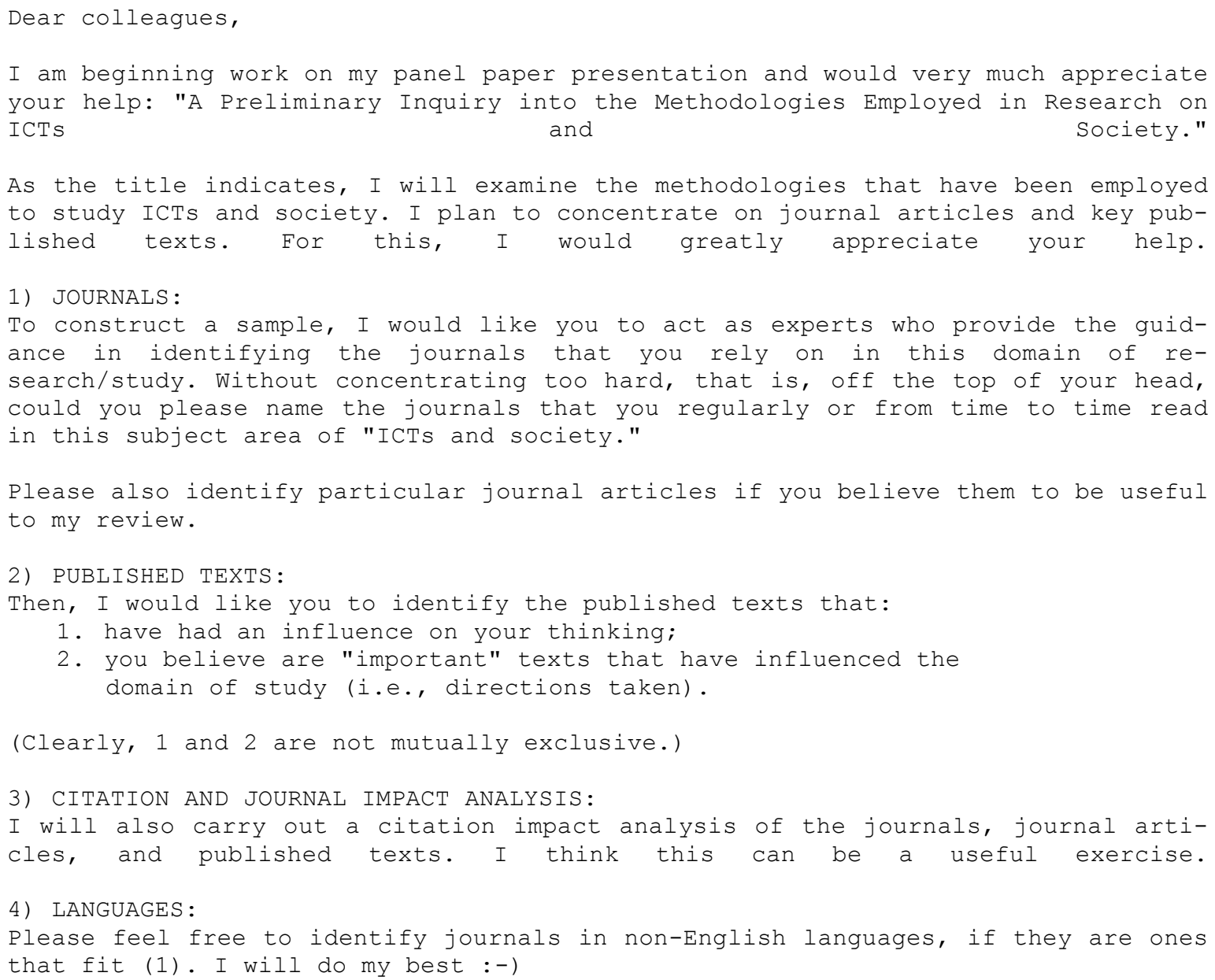

\footnotetext{
${ }^{6}$ See "Transdisciplinarity as Main Principle, Interdisciplinarity as Necessity" available at: http://www.icts.sbg.ac.at/media/pdf/pdf446.pdf
} 
Thank you all in advance for your help in preparing this panel presentation.

With best wishes and until the Algarve conference,

Alice

Bradley provided a list of 12 journals $^{7}$ and Hofkirchner and his colleagues, 36 journals, for a total of 45 journals with an overlap of three journals. ${ }^{8}$ After this list was obtained, the Scopus and Web of Science (WoS) databases that index journals were queried to identify: (1) the subject areas/categories that the databases apply to these journals (in cases where more than one subject category was assigned to a journal, only the first one was used here); (2) the impact factor scores and ranking of the 45 journals within their respective subject areas/categories. Scopus indexed 32 and WoS indexed 20 of the 45 journals. See Table 1 for the list of 45 unique journals with information about only one of their assigned categories, number of journals in that category, 2007 journal impact score, and rank order of journal in that category. Notice how many more journals are indexed by Scopus than by Web of Knowledge. (This leads to my colleague Meho's recommendation that I rely on Scopus for future journal sampling, which he describes in footnote 10.) Also, it should be noted that, as later indicated in Tables 2 and 3, many of these journals had multiple categories and sometimes more than one subject area assigned to them (See Leydesdorff and Probst's (2009) discussion about this situation.)

\begin{tabular}{|c|c|c|c|c|c|c|c|c|c|c|c|c|c|c|}
\hline $\ln$ & sco & Cat & Total N & Impact & Rank & In & WoK & Cat & al & Impact & Rank & IU & Journal Name & Source \\
\hline $\mathrm{R}$ & $x$ & SOC/PS & 231 & 2,19 & 10 & & & & & & & $x$ & Annual Review of Sociology & WH \\
\hline 1 & $\mathrm{x}$ & $\mathrm{CS} / \mathrm{HCl}$ & 25 & 1,54 & 9 & & & & & & & $x$ & Behaviour and Information Technology & GB \\
\hline 2 & $\mathrm{x}$ & GEO & 412 & 0,24 & 184 & & & & & & & $x$ & [Bulletin of ] Science, Technology \& Society (Sage) & WH \\
\hline 3 & $\mathrm{x}$ & GEO & 412 & 0,55 & 93 & & & & & & & $x$ & Cognition, Technology and Work & GB \\
\hline 4 & $\mathrm{x}$ & SOFTWA & 159 & 1,37 & 30 & & & & & & & $x$ & Computer Supported Cooperative Work & GB \\
\hline \multirow[t]{4}{*}{5} & $\mathrm{x}$ & COM & 36 & 0,09 & 31 & 1 & $\mathrm{x}$ & COM & 45 & 0,149 & 44 & $x$ & Critical Studies in Media Communication (Taylor \& Francis) & WH \\
\hline & & & & & & & & & & & & & Cybernetics and Human Knowing (Imprint Academic) & WH \\
\hline & & & & & & & & & & & & & Electronic Journal of Communication & WH \\
\hline & & & & & & & & & & & & & European Journal of ePractice & WH \\
\hline 6 & $\mathrm{x}$ & LANG & 62 & 0,65 & 25 & 2 & $\mathrm{x}$ & COM & 45 & 0,634 & 26 & $\mathrm{x}$ & European Journal of Communication (Sage) & WH \\
\hline 7 & $\mathrm{x}$ & IS & 107 & 1,17 & 36 & 3 & $\mathrm{x}$ & $\mathrm{CS} / \mathrm{IS}$ & 92 & 0,712 & 55 & $x$ & European Journal of Information Systems & GB \\
\hline \multirow[t]{2}{*}{8} & $\mathrm{x}$ & MEDIA T & 20 & 0,38 & 5 & & & & & & & $x$ & First Monday & WH \\
\hline & & & & & & & & & & & & $x$ & Global Media Journal & WH \\
\hline 9 & $x$ & $\mathrm{HCl}$ & 25 & 1,57 & 8 & 4 & $\mathrm{x}$ & CS/CYBE & 17 & 2,476 & 1 & $x$ & Human-Computer Interaction & GB \\
\hline 10 & $\mathrm{x}$ & MIS & 35 & 2,32 & 3 & 5 & $\mathrm{x}$ & $\mathrm{CS} / \mathrm{IS}$ & 92 & 1,631 & 21 & $x$ & Information and Management (Elsevier) & GB \\
\hline 11 & $\mathrm{x}$ & MIS & 35 & 2,04 & 5 & & & & & & & $x$ & Information and Organization & GB \\
\hline 12 & $\mathrm{x}$ & COM & 36 & 0,85 & 12 & & & & & & & $x$ & Information, Communication \& Society (Taylor \& Francis) & GB/WH \\
\hline 13 & $x$ & LIS & 92 & 1,26 & 22 & 6 & $x$ & IS/LS & 56 & 0,719 & 27 & $x$ & Information Society (Taylor \& Francis) & WH \\
\hline 14 & $\mathrm{x}$ & MIS & 35 & 1,9 & 6 & $7 \mid$ & $\mathrm{x}$ & $\mathrm{CS} / \mathrm{IS}$ & 92 & 1,681 & 20 & $x$ & Information Systems (Wiley) & WH/GB \\
\hline 15 & $\mathrm{x}$ & LIS & 92 & 1,3 & 28 & & & & & & & $x$ & Information Technology and People (ITP) & WH \\
\hline 16 & $\mathrm{x}$ & BUS-IMGT & 123 & 1,44 & 25 & 8 & $\mathrm{x}$ & BUS & 72 & 1,186 & 25 & $x$ & International Journal of Electronic Commerce & WH \\
\hline \multirow[t]{3}{*}{17} & $x$ & $\mathrm{HCl}$ & 25 & 0,84 & 12 & 9 & $\mathrm{x}$ & ERGON & 13 & 0,381 & 13 & $\mathrm{x}$ & International Journal of Human-Computer Interaction & GB \\
\hline & & & & & & & $x$ & & & & & $x$ & International Journal of Internet Science: & WH \\
\hline & & & & & & & & & & & & & International Review of Information Ethics & WH \\
\hline 18 & $\mathrm{x}$ & COM & 36 & 0,18 & 26 & 10 & $\mathrm{x}$ & COM & 45 & 0,151 & 43 & $x$ & Javnost-The Public & WH \\
\hline 19 & $\bar{x}$ & C & 416 & 0,36 & 191 & 11 & $\mathrm{x}$ & COM & 45 & 0,382 & 36 & $x$ & Journal of Broadcasting \& Electronic Media & WH \\
\hline 20 & $\mathrm{x}$ & COM & 36 & 1,33 & 8 & 12 & $\mathrm{x}$ & COM & 45 & 1,156 & 15 & $x$ & Journal of Communication (Wiley) & WH \\
\hline \multirow[t]{5}{*}{21} & $x$ & $\& \mathrm{COM}$ & 109 & 1,48 & 25 & 13 & $\mathrm{x}$ & COM & 45 & 1,232 & 12 & $x$ & Journal of Computer Mediated Communication (JCMC) & WH \\
\hline & & & & & & & & & & & & $\mathrm{x}$ & Journal of Community Informatics & WH/GB \\
\hline & & & & & & & & & & & & $\mathrm{x}$ & Journal of Communication Inquiry (Sage) & WH \\
\hline & & & & & & & & & & & & $x$ & Journal of Information, Communication and Ethics in Society & WH \\
\hline & & & & & & & & & & & & $x$ & Journal of Online Behavior & WH \\
\hline 22 & $\mathrm{x}$ & IS & 107 & 1,21 & 36 & & & & & & & $x$ & Knowledge and Information Systems (Springer) & GB \\
\hline 23 & $\mathrm{x}$ & SOC/PS & 231 & 0,71 & 90 & 14 & $\mathrm{x}$ & COM & 45 & 0,641 & 25 & $x$ & Media, Culture \& Society (Sage) & WH \\
\hline
\end{tabular}

\footnotetext{
${ }^{7}$ Bradley apologized for the "small" number of journals, explaining that in recent years she has reduced the journals because she is heavily involved as a senior scholar with extensive commitments. Another analysis will be specifically directed to her work since the 1970s and it is expected that this investigation will yield additional journals.

${ }^{8}$ One additional journal was added to the list, Human-Computer Interaction, because I could not determine whether this journal and/or the International Journal of Human-Computer Interaction was the intended one.
} 


\begin{tabular}{|r|r|l|r|r|r|r|r|r|r|r|r|r|l|l|}
\hline 24 & $\mathrm{x}$ & COM & 36 & 0,59 & 19 & 15 & $\mathrm{x}$ & $\mathrm{COM}$ & 45 & 0,488 & 29 & $\mathrm{x}$ & New Media and Society (Sage) \\
\hline & & & & & & & & & & & & $\mathrm{x}$ & Nordicom Review \\
\hline & & & & & & & & & & & & & OberCom - Research and Knowledge in Communication & WH \\
\hline 25 & $\mathrm{x}$ & $\mathrm{PHIL}$ & 37 & 0,24 & 13 & 16 & $\mathrm{x}$ & $\mathrm{ETHICS}$ & 28 & 0,39 & 21 & $\mathrm{x}$ & Philosophy of the Social Sciences (Sage) \\
\hline & & & & & & & & & & & & $\mathrm{x}$ & Philosophy \& Social Criticism (Sage) \\
\hline $\mathrm{R}$ & $\mathrm{x}$ & SOC/PS & 231 & 0,21 & 153 & 17 & $\mathrm{x}$ & $\mathrm{POLSCl}$ & 93 & 0,156 & 81 & $\mathrm{x}$ & Political Quarterly (Wiley Blackwell) \\
\hline & & & & & & & & & & & & $\mathrm{x}$ & Review of Communication (Taylor \& Francis) \\
\hline 26 & $\mathrm{x}$ & GEO & 412 & 0,86 & 51 & & & & & & & & Science and Public Policy \\
\hline 27 & $\mathrm{x}$ & SOC/PS & 231 & 1,5 & 24 & 18 & $\mathrm{x}$ & SOCSCI & 32 & 1,711 & 3 & $\mathrm{x}$ & Science, Technology \& Human Values (Sage) \\
\hline 28 & $\mathrm{x}$ & CS Theory & 120 & 0,46 & 98 & 19 & $\mathrm{x}$ & LIS & 56 & 0,405 & 39 & $\mathrm{x}$ & Social Science Computer Review (Sage) \\
\hline 29 & $\mathrm{x}$ & BUS IMGT & 123 & 0,82 & 45 & 20 & $\mathrm{x}$ & $\mathrm{COM}$ & 45 & 0,593 & 27 & $\mathrm{x}$ & Telecommunications Policy (Elsevier) \\
\hline 30 & $\mathrm{x}$ & $\mathrm{T}$ & 109 & 0,47 & 62 & & & & & & & & Telematics \& Informatics (Elsevier) \\
\hline 31 & $\mathrm{x}$ & IS & 107 & 1,16 & 38 & & & & & & & $\mathrm{x}$ & Universal Access in the Information Society \\
\hline 32 & $\mathrm{x}$ & $\mathrm{HCl}$ & 25 & 0,77 & 14 & & & & & & & $\mathrm{x}$ & Webology \\
\hline
\end{tabular}

Table 1: Scopus and Web of Knowledge Databases: Journals by Subject Category, Impact, and Rank

The second stage in developing a core journal in the domain area ranked these journals by impact factor within category(ies) in order to select a sample of journals whose articles would later be investigated to determine the methodologies that had been employed by scholars who study ICTs and society. I coded the journals for all subject categories and impact factors that were identified by Journal Citation reports and SCImago. ${ }^{9}$ Two journals were removed from the list because they are "general purpose" disciplinary journals (Political Science Quarterly, Annual Review of Sociology). I then consulted my colleague Lokman Meho about the significant difference in the number of journals indexed by Scopus and WoS. He recommended that I rely on Scopus to draw my sample of journals to select articles that would be examined at a later time. ${ }^{10}$ Table 2 identifies the 32 journals indexed by Scopus with their subject area and subject categories.

Behaviour and Information Technology

Subject Area: Computer Science

Subject Category: Human-Computer Interaction

Cognition, Technology and Work

Subject Area: Social Sciences

Subject Category: Geography, Planning and Development

Computer Supported Cooperative Work: CSCW: An International Journal

Subject Area: Computer Science

Subject Category: Software

Critical Studies in Media Communication

Subject Area: Social Sciences

Subject Category: Communication

European Journal of Communication

Subject Area: Arts and Humanities

Subject Category: Language and Linguistics

European Journal of Information Systems

Subject Area: Computer Science

Subject Category: Information Systems

First Monday

Subject Area: Engineering

Subject Category: Media Technology

\footnotetext{
${ }^{9}$ Journal Citation Reports is based on data from Web of Science, whereas SCImago is based on data from Scopus (see http://www.scimagojr.com/).

${ }^{10}$ Personal correspondence (May 4, 2009): "Scopus covers more than $85 \%$ of all the titles covered in WoS, whereas WoS covers only $57 \%$ of the titles covered in Scopus. So, yes, you can rely solely on Scopus. The difference is only because Scopus indexes approximately 15,000 titles, whereas WoS indexes approximately 9,000 titles."
} 


\begin{tabular}{|c|}
\hline $\begin{array}{l}\text { Human-Computer Interaction } \\
\text { Subject Area: Computer Science | Mathematics } \\
\text { Subject Category: Computational Theory and Mathematics | Human-Computer Interaction | } \\
\text { Theoretical Computer Science }\end{array}$ \\
\hline $\begin{array}{l}\text { Information and Management } \\
\text { Subject Area: Business, Management and Accounting } \\
\text { Subject Category: Management Information Systems }\end{array}$ \\
\hline $\begin{array}{l}\text { Information and Organization } \\
\text { Subject Area: Business, Management and Accounting } \\
\text { Subject Category: Management Information Systems }\end{array}$ \\
\hline $\begin{array}{l}\text { Information, Communication \& Society } \\
\text { Subject Area: Social Sciences } \\
\text { Subject Category: Communication | Social Sciences (Miscellaneous) }\end{array}$ \\
\hline $\begin{array}{l}\text { Information Society } \\
\text { Subject Area: Social Sciences } \\
\text { Subject Category: Library and Information Science }\end{array}$ \\
\hline $\begin{array}{l}\text { Information Systems } \\
\text { Subject Area: Business, Management and Accounting } \\
\text { Subject Category: Management Information Systems }\end{array}$ \\
\hline $\begin{array}{l}\text { Information Technology and People } \\
\text { Subject Area: Business, Management and Accounting | Computer Science | Decision Sciences | } \\
\text { Social Sciences } \\
\text { Subject Category: Information Systems | Information Systems and Management | Library and } \\
\text { Information Sciences | Management of Technology and Innovation }\end{array}$ \\
\hline $\begin{array}{l}\text { International Journal of Electronic Commerce } \\
\text { Subject Area: Business, Management \&Accounting | Economics, Econometrics and Finance } \\
\text { Subject Category: Business and International Management | Economics and Econometrics }\end{array}$ \\
\hline $\begin{array}{l}\text { International Journal of Human-Computer Interaction } \\
\text { Subject Area: Computer Science } \\
\text { Subject Category: Human-Computer Interaction }\end{array}$ \\
\hline $\begin{array}{l}\text { Javnost-The Public } \\
\text { Subject Area: Social Sciences } \\
\text { Subject Category: Communication }\end{array}$ \\
\hline $\begin{array}{l}\text { Journal of Broadcasting \& Electronic Media } \\
\text { Subject Area: Engineering } \\
\text { Subject Category: Electrical and Electronic Engineering }\end{array}$ \\
\hline $\begin{array}{l}\text { Journal of Communication } \\
\text { Subject Area: Social Sciences } \\
\text { Subject Category: Communication }\end{array}$ \\
\hline $\begin{array}{l}\text { Journal of Computer-Mediated Communication } \\
\text { Subject Area: Computer Science } \\
\text { Subject Category: Computer Networks and Communications }\end{array}$ \\
\hline $\begin{array}{l}\text { Knowledge and Information Systems } \\
\text { Subject Area: Computer Science } \\
\text { Subject Category: Information Systems }\end{array}$ \\
\hline $\begin{array}{l}\text { Media, Culture \& Society } \\
\text { Subject Area: Social Sciences } \\
\text { Subject Category: Sociology and Political Science }\end{array}$ \\
\hline $\begin{array}{l}\text { New Media \& Society } \\
\text { Subject Area: Social Science } \\
\text { Subject Category: Communication | Social Sciences (Miscellaneous) }\end{array}$ \\
\hline
\end{tabular}




\begin{tabular}{|c|c|}
\hline Philosopl & $\begin{array}{l}\text { hy of the Social Sciences } \\
\text { Subject Area: Arts and Humanities } \\
\text { Subject Category: Philosophy }\end{array}$ \\
\hline Science $a$ & $\begin{array}{l}\text { and Public Policy } \\
\text { Subject Area: Social Sciences } \\
\text { Subject Category: Geography, Planning and Development }\end{array}$ \\
\hline Science, & $\begin{array}{l}\text { Technology and Human Values } \\
\text { Subject Area: Social Sciences } \\
\text { Subject Category: Social Sciences (Miscellaneous) }\end{array}$ \\
\hline [Bulletin & $\begin{array}{l}\text { of] Science, Technology \& Society } \\
\text { Subject Area: Social Sciences } \\
\text { Subject Category: Geography, Planning and Development }\end{array}$ \\
\hline Social Sc & $\begin{array}{l}\text { ience Computer Review } \\
\text { Subject Area: Computer Science | Social Sciences } \\
\text { Subject Category: Computational Theory and Mathematics | Computer Science Applications | } \\
\text { Library and Information Science | Social Sciences (Miscellaneous) }\end{array}$ \\
\hline Telecomn & $\begin{array}{l}\text { munications Policy } \\
\text { Subject Area: Business, Management \& Accounting | Computer Science | Social Sciences } \\
\text { Subject Category: Business and International Management | Communication | Development | } \\
\quad \text { Information Systems | Library and Information Sciences | Sociology and Political Science }\end{array}$ \\
\hline Telematic & $\begin{array}{l}\text { cs and Informatics } \\
\text { Subject Area: Computer Science } \\
\text { Subject Category: Computer Networks and Communications }\end{array}$ \\
\hline Universal & $\begin{array}{l}\text { l Access in the Information Society } \\
\text { Subject Area: Computer Science } \\
\text { Subject Category: Information Systems }\end{array}$ \\
\hline Webology & $\begin{array}{l}y \\
\text { Subject Area: Computer Science | Decision Sciences | Social Sciences } \\
\text { Subject Category: Human-Computer Interaction | Information Systems and Management | } \\
\text { Library and Information Sciences | Software }\end{array}$ \\
\hline
\end{tabular}

Table 2: Subject Area and Categories of Journals Indexed by Scopus

Based on this analysis of journals that my panel colleagues read, we see that these journals reflect scholarly study that is highly interdisciplinary and confirms the assessment of contributors to the special issue of The Information Society. Subject areas indexed by Scopus include: arts and humanities; business, management and accounting; communication; computer science; decision sciences; economics; economics, econometrics and finance; engineering; library and information science; mathematics; and social sciences. There appears to be considerable redundancy between subject areas and subject categories ${ }^{11}$ and some of the assigned subject areas or categories are incorrect (e.g., First Monday, Social Science Computer Review), which is an indication of poor subject indexing or the need to make the subject areas and categories more relevant to contents.

Nonetheless, the subject categories, which I have somewhat reorganized in Table 3, provide insights into the multidisciplinary of the scholarly work on ICTS and society by my two colleagues. ${ }^{12}$ Table 3 reorganizes the journals to indicate all the categories in which a journal is indexed by Scopus (column 6 indicates that a journal is indexed in multiple categories). These categories are reorganized to reflect the major subject category areas of business, communication, computer science,

\footnotetext{
${ }^{11}$ Meho points out that overlap, or assigning multiple categories to a journal, is unavoidable in many cases due to the interdisciplinary nature of the journals. In addition, as Leydesdorff and Probst (2009) point out, indexing is carried out for bibliographic purposes and "not for the purpose of journal or research evaluation" (p. 1715).

${ }^{12}$ There are some differences in how Web of Science categorized the journal subject categories, which suggests a better description than the one applied by Scopus.
} 
development, human-computer interaction, library and information science, (management) information systems, philosophy, and the social sciences. Management information systems (MIS) could be categorized with the other business journals because these are journals that are edited by scholars located in business schools. Much of what contemporary human-computer interaction is about could be classified as a discipline or multiple disciplines of the social sciences. Communication scholars are typically trained in the social sciences (e.g., political science, social psychology).

\begin{tabular}{|c|c|c|c|c|c|}
\hline Category & $\begin{array}{l}\text { Total } \\
\mathbf{N}\end{array}$ & $\begin{array}{l}\text { Impact } \\
\text { Factor }\end{array}$ & Rank & Journal Name & $\begin{array}{c}\text { In More } \\
\text { Than } 1 \\
\text { Category }\end{array}$ \\
\hline BUS-IMGT & 123 & 1,44 & 25 & International Journal of Electronic Commerce & * \\
\hline Econ \& Ecmetrics & 264 & 1,44 & 51 & International Journal of Electronic Commerce & * \\
\hline BUS IMGT & 123 & 0,82 & 45 & Telecommunications Policy (Elsevier) & * \\
\hline CNetworks \& COM & 109 & 1,48 & 25 & $\begin{array}{l}\text { Journal of Computer-Mediated Communication } \\
\text { (JCMC) }\end{array}$ & \\
\hline $\mathrm{COM}$ & 36 & 1,33 & 8 & Journal of Communication (Wiley) & \\
\hline COM & 36 & 0,85 & 12 & $\begin{array}{l}\text { Information, Communication \& Society (Taylor \& } \\
\text { Francis) }\end{array}$ & * \\
\hline $\mathrm{COM}$ & 36 & 0,82 & 13 & Telecommunications Policy (Elsevier) & * \\
\hline LANG & 62 & 0,65 & 25 & European Journal of Communication (Sage) & \\
\hline COM & 36 & 0,59 & 19 & New Media and Society (Sage) & * \\
\hline ELECTRIC & 416 & 0,36 & 191 & Journal of Broadcasting \& Electronic Media & \\
\hline $\mathrm{COM}$ & 36 & 0,18 & 26 & Javnost-The Public & \\
\hline $\mathrm{COM}$ & 36 & 0,09 & 31 & $\begin{array}{l}\text { Critical Studies in Media Communication (Taylor \& } \\
\text { Francis) }\end{array}$ & \\
\hline COMPNET & 109 & 0,47 & 62 & Telematics and Informatics (Elsevier) & \\
\hline CS App & 117 & 0,46 & 73 & Social Science Computer Review (Sage) & * \\
\hline CS Theory & 120 & 0,46 & 98 & Social Science Computer Review (Sage) & * \\
\hline DEV & 126 & 0,82 & 21 & Telecommunications Policy (Elsevier) & * \\
\hline GEO & 412 & 0,86 & 51 & Science and Public Policy & \\
\hline Category & $\begin{array}{l}\text { Total } \\
\mathbf{N}\end{array}$ & $\begin{array}{l}\text { Impact } \\
\text { Factor }\end{array}$ & Rank & Journal Name & $\begin{array}{c}\text { In More } \\
\text { Than } 1 \\
\text { Category }\end{array}$ \\
\hline GEO & 412 & 0,55 & 93 & Cognition, Technology and Work & \\
\hline GEO & 412 & 0,24 & 184 & [Bulletin of] Science, Technology \& Society (Sage) & \\
\hline $\mathrm{HCl}$ & 25 & 1,57 & 8 & Human-Computer Interaction & \\
\hline $\mathrm{HCl}$ & 25 & 1,54 & 9 & Behaviour and Information Technology & \\
\hline SOFTWA & 159 & 1,37 & 30 & Computer Supported Cooperative Work & \\
\hline $\mathrm{HCl}$ & 25 & 0,84 & 12 & International Journal of Human-Computer Interaction & \\
\hline $\mathrm{HCl}$ & 25 & 0,77 & 14 & Webology & \\
\hline IS-MGT & 25 & 1,42 & 7 & Information Technology and People (ITP) & * \\
\hline IS & 107 & 1,3 & 34 & Information Technology and People (ITP) & * \\
\hline IS & 107 & 1,21 & 36 & Knowledge and Information Systems (Springer) & \\
\hline IS & 107 & 1,17 & 36 & European Journal of Information Systems & \\
\hline IS & 107 & 1,16 & 38 & Universal Access in the Information Society & \\
\hline IS & 107 & 0,82 & 55 & Telecommunications Policy (Elsevier) & * \\
\hline IS-MGT & 25 & 0,77 & 13 & Webology & * \\
\hline LIS & 92 & 1,3 & 28 & Information Technology and People (ITP) & * \\
\hline MGT-TEC INNOVA & 115 & 1,3 & 26 & Information Technology and People (ITP) & * \\
\hline LIS & 92 & 1,26 & 22 & Information Society (Taylor \& Francis) & \\
\hline
\end{tabular}




\begin{tabular}{|c|c|c|c|c|c|}
\hline LIS & 92 & 0,82 & 19 & Telecommunications Policy (Elsevier) & * \\
\hline LIS & 92 & 0,77 & 39 & Webology & * \\
\hline LIS & 92 & 0,46 & 16 & Social Science Computer Review (Sage) & * \\
\hline MEDIA T & 20 & 0,38 & 5 & First Monday & \\
\hline MIS & 35 & 2,32 & 3 & Information and Management (Elsevier) & \\
\hline MIS & 35 & 2,04 & 5 & Information and Organization & \\
\hline MIS & 35 & 1,9 & 6 & Information Systems Journal (Wiley) & \\
\hline PHIL & 37 & 0,24 & 13 & Philosophy of the Social Sciences (Sage) & \\
\hline SOC/PS & 231 & 1,5 & 24 & Science, Technology, \& Human Values (Sage) & \\
\hline SocSci M & 318 & 0,85 & 58 & $\begin{array}{l}\text { Information, Communication \& Society (Taylor \& } \\
\text { Francis) }\end{array}$ & * \\
\hline SOC/PS & 231 & 0,82 & 75 & Telecommunications Policy (Elsevier) & * \\
\hline SOC/PS & 231 & 0,71 & 90 & Media, Culture \& Society (Sage) & \\
\hline Soc Sci-M & 318 & 0,59 & 85 & New Media and Society (Sage) & * \\
\hline Soc Sci-M & 318 & 0,46 & 115 & Social Science Computer Review (Sage) & * \\
\hline \multicolumn{6}{|l|}{$\begin{array}{l}\text { Moved to Another } \\
\text { Category }\end{array}$} \\
\hline ELECTRIC & 416 & 0,36 & 191 & Journal of Broadcasting \& Electronic Media & \\
\hline LANG & 62 & 0,65 & 25 & European Journal of Communication (Sage) & \\
\hline SOFTWA & 159 & 1,37 & 30 & Computer Supported Cooperative Work & \\
\hline Econ \& Ecmetrics & 264 & 1,44 & 51 & International Journal of Electronic Commerce & \\
\hline IS-MGT & 25 & 1,42 & 7 & Information Technology and People (ITP) & \\
\hline \multicolumn{6}{|l|}{ Removed Entirely } \\
\hline SOC/PS & 231 & 2,19 & 10 & Annual Review of Sociology & \\
\hline SOC/PS & 231 & 0,21 & 153 & Political Quarterly (Wiley Blackwell) & \\
\hline \multicolumn{6}{|c|}{ These journals were not indexed by Scopus: } \\
\hline \multicolumn{6}{|c|}{ Cybernetics and Human Knowing (Imprint Academic) } \\
\hline \multicolumn{6}{|c|}{ European Journal of ePractice } \\
\hline \multicolumn{6}{|c|}{ Global Media Journal } \\
\hline \multicolumn{6}{|c|}{ International Journal of Internet Science: } \\
\hline \multicolumn{6}{|c|}{ International Review of Information Ethics } \\
\hline \multicolumn{6}{|c|}{ Journal of Community Informatics } \\
\hline \multicolumn{6}{|c|}{ Journal of Communication Inquiry (Sage) } \\
\hline \multicolumn{6}{|c|}{ Journal of Information, Communication and Ethics in Society } \\
\hline \multicolumn{6}{|c|}{ Journal of Online Behavior } \\
\hline \multicolumn{6}{|l|}{ Nordicom Review } \\
\hline \multicolumn{6}{|c|}{ OberCom - Research and Knowledge in Communication } \\
\hline \multicolumn{5}{|c|}{ Philosophy \& Social Criticism (Sage) } & \\
\hline Review of Commu & or \& F & & & & \\
\hline
\end{tabular}

Table 3: Journals Indexed by Scopus: By Impact Factor and Rank within All Identified Categories (Reorganized)

How now to select journals for evaluating their articles in order to identify the methodologies that have been employed? Reorganizing journals according to their categories and then organizing these journals by their impact factor suggests a strategy for selecting a sample of journals. Within each category, and taking account of the multiple categories in which a journal has been indexed, 
journals with an impact factor of greater than 1.0 will be selected, but I will also consult my experts and an infometrician. ${ }^{13}$ My hope is that this strategy will yield a manageable sample of journals to investigate in detail.

\section{What Is "Method"?}

The direction that I took and described in this essay follows the normal trajectory of research. Alford (1998) points out that,

When you begin to define a research question, you have to find out what is already known about the general theme or topic. The problem is that it might take months or years to read everything known or relevant, precisely because you can't possibly know the boundaries of the problem at this point. (p. 103)

Rumination is appropriate, he writes, and "even potentially important" (p. 104). The "process of deciding on a research question is neither neat nor straightforward, and you may well decide that the question you are really interested in is [another one]" (p. 104). Throughout this most precious text, Alford emphasizes the appropriateness and necessity of a "playful attitude, an attempt to deal with any and all potential issues before making a commitment to a research design" (p. 104). He urges us to be "self conscious about [our] assumptions and their consequences for the research process" (p. 105).

Methodology is defined, according to a web search for its definition, as "a collection of methods, practices, procedures and rules used by those who work in some field"14; "a system of principles, practices, and procedures applied to a specific branch of knowledge"15; "a documented approach for performing activities in a coherent, consistent, accountable, and repeatable manner" ${ }^{\prime \prime}$; and, most generally, "a set of procedures or methods used to conduct research" ${ }^{17}$ These definitions are, however, more akin to Alford's (1998) remark that these usual definitions of "method" or "methodology" may better reflect the skills training that we get in a research methods course (what Kim and Weaver, 2002, reported).

Alford's (1998) conception of the craft of inquiry suggests, instead, that our task is to examine the relationship between theory, method, and evidence, that is, methods is the connector between theory and evidence. His conception thus sets a higher bar for the investigation of methodologies employed by scholars of ICTs and society.

My assessment of methodologies must be, following Alford, more rigorous than a study of techniques or procedures. Decisions about how to proceed must be both theoretical and empirical and must move back and forth between the theoretical and empirical. Evidence "regarded as relevant is part of the intrinsic process through which you work out a theoretical argument," he counsels ( $p$. 110). Finally, it is worth concluding by reiterating his argument:

The general point, applying to every study, is that the process of considering what specific evidence you will accept for the occurrence of an event cannot be separated from the process of defining the concept, which is itself part of theorizing the "meaning" of the concept (and its relation to other concepts constituting the theory) (p. 118).

\footnotetext{
${ }^{13}$ In a personal communication (May 17, 2009), Meho also recommends that I consider using the following additional method for identifying relevant journals. He writes that "Conducting a keyword search in Scopus and Web of Science (in the title, abstract, and descriptor fields). This will retrieve thousands of records. The next step is to tally the results by journals in which these records appeared (this step is done automatically by the databases)." In other words, both human and machine indexing are necessary.

${ }^{14} \mathrm{http}: / /$ en.wiktionary.org/-wiki/methodology

${ }^{15} \mathrm{http}: / /$ services.eliteral.com/glossary/-decision-support-systems-glossary.php

${ }^{16} \mathrm{http}: / / \mathrm{www}$.ichnet.org/glossary.htm

${ }^{17}$ http://www.usg.edu/galileo/skills/-olic_glossary.phtml
} 


\section{References}

Alford, R. R. (1998). The Craft of Inquiry: Theories, methods, and evidence. New York and Oxford: Oxford University Press.

Baym, N. K. (2005). Introduction: Internet research as it isn't, is, could be, and should be. The Information Society, 21(4), 229-232.

Bradley, G. (2006). Social and community informatics: Humans on the net. London and New York: Routledge.

Cronin, B. \& Meho, L. I. (2008). The shifting balance of intellectual trade in information studies. Journal of the American Society for Information Science and Technology, 59(4), 551-564.

December, J. (1996). Units of analysis for Internet communication. Journal of Computer-Mediated Communication, 1(4). Retrieved May 12, 2009, from http://jcmc.indiana.edu/vol1/issue4/december.html

Hine, C. (2005) Internet research and the sociology of cyber-social-scientific knowledge. The Information Society, 21(4), 239-248.

Kim, S. T. \& Weaver, D. (2002). Communication research about the Internet: A thematic meta-analysis. New Media \& Society, 25(4), 518-538.

Kritzer, H. M. (1994). Interpretation and validity assessment in qualitative research: The case of H. W. Perry's Deciding to Decide. Law and Society Inquiry, 19, 687-724.

Kritzer, H. M. (1996a). The data puzzle: The nature of interpretation in quantitative research. American Journal of Political Science, 40(1), 1-32.

Kritzer, H. M. (1996b). "Data, data, data, drowning in data": Crafting The Hollow Core. Law and Society Inquiry, 21, 761-804.

Leydesdorff, L. \& Probst, C. (2009). The delineation of an interdisciplinary specialty in terms of a journal set: The case of communication studies. Journal of the American Society for Information Science and Technology, 60(8), 1709-1718.

Lievrouw, L. (2009). New media, mediation, and communication study. Information, Communication \& Society, 12(3), 303325.

Markham, A. N. (2005). Disciplining the future: A critical organizational analysis of Internet studies. The Information Society, 21(4), 257-267.

Rice, R. E. (2005). New Media/Internet research topics of the Association of Internet Researchers. The Information Society, 21(4), 285-299.

Wimmer, R. D. \& Dominick, J. R. (2000). Mass media research: An introduction (6th ed.). Belmont, CA: Wadsworth.

\section{About the Author}

Alice Robbin

Alice Robbin is an associate professor in the School of Library and Information Science, Indiana University and co-director of the Rob Kling Center for Social Informatics at Indiana University Bloomington. She teaches courses in research methods, information policy, and organizational informatics. Her research has appeared in the Journal of the American Society for Information Science and Technology, Internet Research, Annual Review of Information Science and Technology, Administration \& Society, and The Information Society. Her current research projects focus on the political controversy in the United States that took place during the 1990s over the reclassification of racial and ethnic data, integrating theoretical perspectives from political science, sociology, social psychology, and history. The work of her doctoral students examines information behavior on the Internet, digital citizenship, community networks, health information systems, e-government, and breakdown of communication following Hurricane Katrina. 